\title{
'Making the Most of Together-Time': Development of a Health Visitor Led Intervention to Support Children's Early Language and Communication Development at the 2-21/2 Year-Old Review
}

\author{
Cristina McKean ( $\nabla$ cristina.mckean@ncl.ac.uk) \\ Newcastle University https://orcid.org/0000-0001-9058-9813 \\ Rose Watson \\ Teesside University \\ Jenna Charlton \\ Newcastle University \\ Susan Roulstone \\ University of the West of England \\ Caitlin Holme \\ Bristol Speech and Language Therapy Research Unit \\ Vicky Gilroy \\ Institute of Health Visiting \\ James Law \\ Newcastle University
}

\section{Research Article}

Keywords: Language development, Young children, Intervention development, COM-B model, Implementation science, tailored intervention, preventative intervention, shared decision-making, intervention equity

Posted Date: August 10th, 2021

DOI: https://doi.org/10.21203/rs.3.rs-749778/v1

License: (c) (i) This work is licensed under a Creative Commons Attribution 4.0 International License. Read Full License

Version of Record: A version of this preprint was published at Pilot and Feasibility Studies on February 8th, 2022. See the published version at https://doi.org/10.1186/s40814-022-00978-5. 


\section{Abstract}

\section{Background:}

Early interventions to support young children's language development through responsive parent-child interaction have proven efficacy but are not currently delivered universally. A potential universal delivery platform is the Health Visitor (HV) led 2-21/2year old review in England's Healthy Child Programme. It is unclear if it is feasible to offer such interventions through this platform. We report an intervention development process, including extensive stakeholder consultation and co-design to develop an acceptable, feasible and equitable early language intervention for delivery in this context.

\section{Methods:}

The study involved five phases including 13 stakeholder co-design workshops with 7 parents and 39 practitioners (HVs, early years practitioners and speech and language therapists). 1) Identification of existing intervention evidence. 2) Qualitative review of intervention studies extracting candidate target behaviours for intervention and intervention techniques. 3) Co-design workshops with parents and practitioners examining acceptability, barriers and enablers to those behaviours and techniques. Particular attention was paid to diverse family circumstances and the range of barriers which might exist. 4) Findings were analysed using COM-B and theoretical domains frameworks and a prototype intervention model designed. 5) Codesign workshops iteratively refined the proposed model.

\section{Results:}

Practitioners were committed to offering language intervention at the $2-2 \frac{1}{2}$ year old review but were not sure precisely how to do so. Parents/caregivers wanted to be proactive and to have agency in supporting their own children, and to do this as soon as possible. For equitable intervention it must be proportionate, with higher 'intensity' for higher levels of disadvantage, and tailored, offering differing approaches considering the specific barriers and enablers, assets and challenges in each family. The importance and potential fragility of alliances between parent/caregiver and practitioner were identified as key and so strategies to engender successful collaborative partnership are also embedded intervention design.

\section{Conclusion:}

It is possible to develop an acceptable, feasible and equitable universal intervention for use at the $2-2 \frac{1}{2}$ year review to promote children's language development. The result is one of the most explicitly developed universal interventions to promote children's language development. Further development and piloting is required to develop materials to support successful widespread implementation.

\section{Key Messages Regarding Feasibility}

1) What uncertainties existed regarding the feasibility?

- Early interventions to support young children's language development through responsive parent-child interaction have proven efficacy but are not currently delivered universally.

- A potential universal delivery platform is the Health Visitor (HV) led 2-21/2 year old review in England's Healthy Child Programme.

- It is unclear if it is feasible to offer such interventions through this platform

2) What are the key feasibility findings?

- It is possible to develop an acceptable, feasible and equitable universal intervention for use at the $2-2 \frac{1}{2}$ year review to promote children's language development

- For equitable intervention it must be proportionate, with higher 'intensity' for higher levels of disadvantage, and tailored, offering differing approaches considering the specific barriers and enablers, assets and challenges in each family.

- The importance and potential fragility of alliances between parent/caregiver and practitioner were identified as key and so strategies to engender successful collaborative partnership are essential for success and must also be embedded intervention design

3) What are the implications of the feasibility findings for the design of the main study?

- The intervention devised provides a protocol for delivery which participants felt were acceptable, feasible and equitable however it is untested in practice.

- Further work is also needed for ELIM-I to be accessible to families from a range of linguistic and cultural backgrounds.

- Further work is required to develop and pilot a manualised program with standardised intervention resources and guidance for local implementation and policy development.

\section{Background}


The early years of a child's life lay the foundation for their health, education and wellbeing across the life-course [1, 2]. A child's language development in these early years is a key component of that foundation and is now widely recognised as a crucial indicator of an individual's 'life chances'[3]. Children who enter school (aged 5-6 years) with language difficulties are at risk of poorer long-term outcomes with respect to adolescent educational attainment and social-emotional well-being,[4] adult literacy, mental health, employment [5, 6], health literacy [7], social anxiety and isolation.[8] Given that prevalence estimates suggest that, on average, every primary-school classroom in England contains two children with significant language difficulties [9], reaching up to $40 \%$ in the most disadvantaged communities [10], this is a substantial challenge for educational, social and health services.

Many social and educational policies around the world make robust early language development a key objective [11-13]. Recently, the case has been made that early language and communication needs should be tackled through public health, preventive models of intervention [14]. In the UK Public Health England (PHE) aims to, "improve the health of babies, children and their families to enable a happy healthy childhood and provide the foundations of good health into adult life" [15] through the Healthy Child Programme (HCP) and commissioned by local authorities since 2015 [16, 17]. In 2018 PHE published guidance on the six early years high impact areas; these are areas where Health Visiting (HV) services can make the greatest difference, which include "Health, wellbeing and development of the child aged 2: Ready to learn, narrowing the 'word gap"'[18]. Whilst such ambitions and their rationale are clearly stated in policy precisely how to ensure all children are supported to achieve positive language outcomes is less well specified. Furthermore, whilst The HV 2-21/2 year old review has been the focus of timely identification of speech, language and communication needs using the Ages and Stages Questionnaire (ASQ-3) nationally mandated pre-assessment tool [19], the mode, content and delivery of this contact is variable and interventions commonly lack conceptual and practical detail. In recognition of this the Department for Education (DfE) commissioned a program of training and research to develop a national approach to support the development of children's early language and led by PHE [20]. This research strand developed a novel tool for HV teams to identify children at risk of poor language development and a linked intervention: the Early Language Identification Measure and Intervention - ELIM-I [21, 22]. Here we focus on the development of the intervention component of the ELIM-I whilst a description of the development of the identification measure is reported elsewhere [23].

A great deal is known about the aspects of a child's early learning environment which can be harnessed to promote positive language outcomes in the pre-school period due to several systematic reviews, and efficacy and epidemiological studies [24-32]. Despite this, the development of an intervention, which can be delivered universally, affordably, and effectively for children under the age of 3 years, has remained elusive.

This paper outlines the development of a universal intervention to offer to families at the HV 2-21/2 year old review to promote robust language development for all children. Our aim was to develop an intervention which aligns with the aims, principles and structure of the modernised HCP [33]. That is, an approach with 'universal reach and a personalised response' to be led by HV teams in England, and which focusses, in the first instance, on the universal $2-2 \frac{1}{2}$ year old review and draws on the wider children's workforce, as necessary. Following guidance on the development of complex and public health interventions we sought to develop an intervention which is acceptable, equitable, practicable and can be delivered at scale and which is based on current best evidence and underpinned by relevant theory [34-36]. This paper reports the development of that interventions following recognised guidance (GUIDED)[37]

As with any public health intervention, there is a risk that universal approaches can inadvertently widen rather than narrow inequalities if the necessary attention is not paid to structural factors which influence a family's ability to engage in a given health promoting behaviour [38]. There is evidence to suggest this is a real risk for early language interventions $[39,40]$. An alternative is to apply 'proportionate universalism' where intensity of action is proportionate to the level of disadvantage [41]. However, intensity is not the only characteristic which can and should be tailored to the individual circumstances of a family. Much of the existing evidence regarding pre-school language interventions focusses on building capacity in parents/caregivers: their knowledge and skills as to how to create a language enriching environment for their child. Insufficient attention has been paid to other factors associated with structural inequalities such as families' opportunities and resources as well as affective factors such as their optimism and belief about their capabilities $[42,43]$. For an equitable intervention to be designed we must not only create a proportionate model (i.e. with higher 'intensity' for higher levels of disadvantage need [41]) but also a tailored one, offering differing approaches considering the specific barriers and enablers, assets and challenges in each family [44].

The Medical Research Council's guidance for the development and evaluation of complex interventions emphasises the importance of rigorous intervention development [34], however it is only relatively recently that detailed, systematic and replicable methods for this first phase of intervention research have been specified [42,45]. The following outlines how our approach aligns with the most recent (2019) guidance for the development of complex interventions for health and healthcare by O'Caithan and colleagues [35]. This guidance outlines 5 principles and 10 actions which, if considered, increase the likelihood of effectiveness and enable the widespread adoption of novel interventions in the real world (Table 1).

Our methods were an adaptation of those described by O'Brien and colleagues [45]. This iterative and sequential method is designed to enable the integration of published scientific evidence, expert knowledge and experience and detailed consideration of stakeholder knowledge and views. We remained open to change and processes were developed and adapted as necessary in response to outcomes at each stage. We made use of the expertise of the research team at several stages to challenge, develop and contextualise intervention development. The team comprised researchers with backgrounds in Speech and Language Therapy, General Practice, Health Visiting (practice and policy), Psychology, Medical Sociology, and Linguistics. In addition, reflections from a parallel study regarding the acceptability of the ELIM/developmental review were used to challenge interpretations/analyses [46]. 
We drew on existing theory in several ways. First, with respect to child language development, we were informed by socio-cognitive theories [47-49] which emphasise the importance of responsive interactions with caregivers for robust language development. A number of infant socio-cognitive skills are also crucial to early language development: the ability to share attention with adults, understand their communicative intentions and take turns in conversations [50]. Language is learned best in responsive social interactions between caregiver and infant where the language used by the adult is contingent on the child's attention and where the child is deploying these socio-cognitive abilities to infer meaning and maintain the interaction $[29,31,32,50]$. Importantly caregiver responsive, contingent interactions also facilitate the development of these socio-cognitive abilities and so are critical to robust language and communication development from the very earliest days of a child's life [51]. Second, we planned to apply Behaviour Change Theory to the intervention development drawing on the Behaviour Change Wheel [42] and the Theoretical Domains Framework (TDF) [43]. Third, the Theoretical Framework of Acceptability (TFA) [52] informed the development of stakeholder co-design workshop materials.

As data were collected and analysed it became clear that consideration of the socio-relational aspects of the intervention was essential and must inform intervention design if an effective and acceptable approach was to be developed. Additional theory relating to principles of shared decisionmaking, therapeutic alliance, trust, and engagement, were therefore also consulted [36, 53-60].

When attending to future implementation, normalisation theory was also considered [61]. Embedding health care innovations into routine practice is not straightforward and requires explicit planning. Normalisation process theory suggests that four kinds of work need to occur for an innovation to become 'normalised' practice: coherence work (or sense-making); participation work (or engagement); enacting work (action to enable the intervention to happen); and appraisal work (reflection and monitoring of the benefits and costs) [62]. When designing the intervention, where HV teams were on the 'journey' towards normalisation of support for children's language development was considered to ensure the approach devised takes then necessary next steps. Future implementation was also considered through the lens of acceptability throughout the stages of development [52]. The iterative design process was informed by appraisal of our suggested intervention approaches and materials against APEASE criteria (Affordability Practicability, Effectiveness and cost-effectiveness, Acceptability, Safety and Equity [42].

In conclusion the aim was to develop an intervention that is

- Acceptable, practicable and can be delivered at scale.

- Based on current best evidence and underpinned by relevant theory.

- Proportionate to the assets and challenges of individual families.

- Tailored to the barriers and enablers present for individual families.

- Well-specified in its methods to enable fidelity in delivery.

\section{Methods}

Design

An iterative design process was followed through which evidence was gathered and appraised, relevant theory identified and applied, and intervention models and materials generated, tested and analysed. There were five stages, each stage resulting in outputs which then formed the basis of the next phase. (Figure 1). Stages 3 and 5 comprised co-design workshops with parents and practitioners. A total of 13 stakeholder co-design workshops were completed - seven in Stage 3 and six in Stage 5 (Table 2). Members of the research team reflected on and discussed processes and outputs over the course of the study. A number of Public Patient Involvement (PPI) workshops also contributed to knowledge of the context of the interventions.

\section{Ethics}

All relevant details about the project were submitted to the West Midlands - Black Country NHS Research Ethics Committee (REC) and a favourable ethical opinion was received on 7th of May 2019 REC reference 19/WM/0114 project \# 261205. R\&D management approvals were then received from the five sites involved in the study. Participants gave fully informed consent before each workshop/data collection episode.

\section{Sites}

PHE led a selection process to identify 5 sites to host the ELIM-I study based on prevalence of SLCN (as indicated by school readiness), prevalence of risk factors associated with SLCN (including free school meal eligibility as a proxy for socio-economic status and English as an additional language), and the availability of site data. The sites included a mix of urban, rural, northern and southern geographies and a range of service delivery models [23].

\section{Participants}

Study contacts at each site provided meeting facilities and acted as gatekeepers to participant recruitment. For practitioners, study contacts were asked to invite members of the HV team (HVs and Community Nursery Nurses (CNN)) and relevant members of the Speech and Language Therapy (SLT) team. For parents/caregivers they were asked to invite parents of children aged $3-6$ years currently receiving support for their SLCN. This was to allow us to engage with the experiences of families with recent experience of the pathway from identification to receipt of support. Seven parents 
were involved across the workshops. Two parents attended two co-design workshops and five attended one. Parents were given shopping vouchers as a token of appreciation for their time and their travel expenses were reimbursed. Thirty-nine different practitioners were involved across the workshops.

A range of practitioner roles were represented with the substantial majority being HVs or Community Nursery Nurses working within the HV team. This allowed, in particular, for issues of acceptability, practicability, implementation and equity to be explored. SLTs were also represented to draw on their knowledge of local SLCN pathways and of successful language intervention models and techniques. A total of seven different parents/caregivers participated, one of whom spoke English as an Additional Language, and 36 different practitioners (18 HVs, 6 Community Nursery Nurses, 2 Student HVs 1 Family Nurse, 1 Student Nurse, 6 Speech and Language Therapists, 2 Speech and Language Therapy Assistants). Parent/caregiver participant recruitment was affected by the government restrictions associated with COVID-19. Attendance at offered workshops in sites 4 and 2 were probably affected by growing anxiety at that time and a final planned workshop in site 5 with twelve families recruited had to be cancelled due to travel restrictions immediately prior to the first UK lockdown.

Data collection, analysis, and outputs from each stage

Stage 1

Procedures involved compiling the relevant intervention evidence and defining the scope and boundaries of the intervention. A number of scoping and systematic reviews of pre-school interventions with oral language as an outcome had recently been completed by members of the study team or were in progress. To maximise efficiency studies were identified through these four reviews and two additional reviews known to the team [25, 26, 63-66]. Original research studies were identified and sourced from those reviews which had oral language as the outcome, involved parents as the agents of intervention and included children aged between 12 and 36 months. This yielded 27 papers. Discussion with the team suggested a widening of the scope to include studies with mental health and wellbeing or educational outcomes to increase the learning which could be drawn from studies involving HVs and family nurses. The EIF guidebook of early intervention programs that have been evaluated and shown to improve outcomes was consulted [67] and 2 additional papers were identified. A workshop was then conducted with the study expert team which involved 1) an appraisal of the quality and relevance of the available evidence, 2) identification of additional papers to consider and 3) potential barriers and enablers for families when accessing the identified interventions.

Outputs

- Understanding of potential barriers and enablers to the published intervention approaches.

- Broad parameters of the intervention delivery and how it might integrate with identification measure component of the ELIM-I.

- Final list of 16 papers of effective interventions to examine for target behaviours and intervention techniques, which fit these intervention delivery parameters (Listed in Supplementary Materials 1).

- Simple initial logic model of the intervention to guide development (Figure 2).

Stage 2

Procedures involved analysis of the intervention papers identified in stage 1 to extract the target behaviours of the effective interventions and the intervention techniques used in preparation to seek stakeholder's views on this detail in Stage 3. Furthermore, in order to be able to explore how any intervention would need to be tailored for different families to ensure equity and proportionality we planned to use 'persona' in our practitioner stakeholder workshops in Stage 3: an approach which draws on software design methodologies [68]. These personas described families with whom the practitioner might work which vary according to characteristics that may affect a family's ability to engage with an intervention and/or the target health promoting behaviour. Their use in our data collection methods aimed to make explicit expert practitioner knowledge and clinical decisionmaking, which can often be tacit or implicit [69]. To develop persona in an objective, empirically based manner and avoid the danger of reductive stereotypes we searched for epidemiological studies which consider how potential barriers and enablers to positive language outcomes cluster within families. The resulting persona were based work by Christensen and colleagues which identified six distinct clusters associated with differing vocabulary growth trajectories in a representative sample of 4000 Australian children and their families [70]. Pen portraits of families representing the risk clusters described were developed using gender neutral names from a range of cultural heritages. Persona were developed for use only with practitioners, parents/caregivers were asked instead to reflect on their own experiences. Workshop materials were designed using the findings above and drawing on behaviour change and acceptability theoretical frameworks [42, 52]. They aimed to elicit parent/caregiver and practitioner opinions regarding the acceptability of intervention target behaviours and techniques and barriers and enablers for families with differing assets and challenges.

\section{Outputs}

- List of target behaviours - these represented the complexity of the intervention literature where multiple goals were targeted within complex interventions falling broadly into three categories: responsive contingent interaction, shared book reading, and focussed stimulation (Table 3 ).

- List of intervention techniques - multiple techniques were identified including video coaching, diary completion, fridge magnet reminders etc. (Table 3). 
- Persona - six descriptions of family persona based on clusters identified by Christensen et al (Table 4).

- Workshop materials to elicit parent/caregiver opinions as to the acceptability and barriers and enablers for each target behaviour and technique

- Workshop materials to elicit practitioner opinions as to the acceptability and barriers and enablers for each target behaviour and technique for the different family persona.

Stage 3

Procedures involved seven co-design workshops with 22 participants which were facilitated by two members of the study team at each workshop (CM and either RW or SR). Practitioner workshops began with questions to understand the local pathway for children with Speech, Language and Communication (SLC) Needs. Parent/caregiver workshops began with an exploration of the participants' motivation for attendance which also uncovered their experiences of the local pathway. A co-design activity was then completed which involved participants being presented in turn with the candidate target behaviours (e.g. shared book reading) and intervention techniques (e.g. diary completion) identified in Stage 2 (Table 3). Barriers and enablers to and acceptability of adopting the target behaviour or implementing the intervention technique were then explored. Paper-based workshop materials were used to stimulate discussions and helped to scaffold and steer the topics covered. These materials were manipulated and annotated during discussions by the study team and participants. All workshops were audio recorded.

\section{Outputs}

- Verbatim transcriptions of the workshops

- Annotated workshop materials

- Field notes made after workshop completion and team reflection.

Stage 4

Procedures involved analysis of data emerging as outputs from the preceding stages. A deductive approach was used to map the barriers and enablers identified in stage 3 and the intervention techniques in stage 2 to the Theoretical Domains Framework (TDF) [71]. Following methods described by Michie and colleagues $[42,72]$ barriers and enablers (from workshops) and intervention techniques found in the reviewed papers were mapped to the Theoretical Domains Framework noting the relevance of the domain. This was done sequentially, starting with data from papers, then from practitioners and then from parents. Identified domains were then mapped to possible intervention functions and those judged to be inappropriate to the intervention context discarded. Finally. relevant Policy categories were identified for the intervention functions chosen. That is the platform/level at which intervention delivery could effectively occur.

Deductive analysis was used to identify comments regarding acceptability of the techniques and behaviours. Inductive analysis was used to identify any themes which were not determined a-priori but which emerged as important to intervention design. A number of socio-relational aspects of intervention delivery were identified as crucial to intervention success.

Finally, a paper model of a proposed intervention was developed based on the identified intervention functions and policy categories. Judgement was used to determine which were the most relevant to the intervention. This judgement was informed by comments on acceptability from the co-design workshops at Stage 3 and, through discussion with the wider team, drawing on knowledge gained of the contextual factors of importance through PPI and from the parallel study regarding the acceptability of the ELIM/developmental review.

\section{Outputs}

- Mapping of Barriers, Enablers and Techniques to the TDF (Table 5)

- Mapping identified domains to Intervention Functions and Policy Categories (Table 5)

- Identification of acceptable behaviours and techniques for intervention (see Results - final model)

- Identification of key intervention delivery characteristics (see Results - final model)

- Paper 'model' of the proposed intervention informed by the above outputs and knowledge of the intervention context

- Workshop materials to support appraisal of the model against APEASE criteria and identification of preferred materials and presentation

\section{Stage 5}

Procedures: involved six co-design workshops with 33 participants facilitated by two members of the study team. Workshops at this stage involved a 'walk through' of the phases of the proposed intervention with paper mock-ups and descriptors of materials and processes. Workshop resources included triggers to comment on how the phases should be presented and what materials should be used. The intervention model was refined and improved iteratively between workshops with modified materials presented at each site in light of previous workshop findings. Participants also were invited to appraise the proposed intervention against APEASE criteria. Discussions were audio recorded and participants manipulated and annotated paper materials during discussions. Verbatim transcripts of discussions were subjected to a content analysis to check and challenge the final model produced. The model was also 'walked through' with a subgroup of the study team part way through the participant data collection (CM, JL, VG, SR). 
Outputs

- Final intervention model and recommendations

\section{Results}

In the following we present the key learning obtained from the phased methodology above and a final intervention model derived through the synthesis of the evidence, and views of stakeholder and expert practitioners. We report in turn on:

- Parent and practitioner views on the need for an intervention

- Acceptable target behaviours, contexts and intervention techniques

- Barriers and enablers to the identified behaviours across families,

- Intervention functions and policy categories

- Key characteristics required for acceptable, equitable and practicable intervention delivery

- The final intervention model.

Parent and practitioner views on the need for an intervention

Using a normalisation framework, the data from practitioners suggested then the PHE SLC 'train the trainer' program was supporting practitioners to do the work of coherence/sense-making and participation/engagement which is required to embed speech, language, and communication interventions into practices at the $2-2 \frac{1}{2}$ year old review. That is, practitioners had an appetite and indeed an enthusiasm to complete this work, see it is aligning with their role and skills and had 'bought in' to delivering interventions to support child language development. However, we found that the next step of enacting the intervention was difficult for practitioners. They were not sure precisely how to deliver support to families and discussions of the potential provision of concrete resources was welcomed.

Prac-WS7: "except we don't have anything specific do we to show, that's the thing. There's nothing that I'm going to go back and I'm going to go in and I'm going to show this because that is what we do. There's nothing set in stone that that's what we use, is there? I think that's probably a big problem because people are going back in, there's not a definite this is a route we need to follow, is there really?"

Parents also articulated an appetite and a need for an intervention at this point in the SLC pathway. They expressed a drive to 'get started' and a feeling of helplessness, frustration and anger if they felt that nothing was happening and their concerns were going unheard. They wanted to feel that they could take action that would help their child.

P-C-WS5: "because...you feel like something is happening which psychologically is good rather than, "We'll wait a year and she'll probably start speaking.... You can be proactive and do things."

P-C-WS2: "When they did his two year one, they didn't say, "Come back in four weeks or two weeks," it was eight months so in that eight months we could have got something started rather than making us just leave it this late".

They emphasised however that the place in the SLC pathway would need to be clear. It must not introduce delays in referring children with severe difficulties and/or broader developmental concerns to SLTs and/or paediatricians/psychologists/audiologists. Rather it should allow those families to begin supporting their child immediately whilst waiting for specialist assessment if that were the appropriate next step.

P-C-W5:" As long as it's made perfectly clear to them that they just can't be left flailing around for two or three years like they have been......And listen to parents because they know if something is wrong."

Acceptable target behaviours, contexts and intervention techniques

\section{Behaviours}

Discussions highlighted that parents and practitioners preferred an approach which would allow them to integrate any new behaviours into their everyday routine, rather than as an additional activity. Practitioners felt that the contingent responsive interaction behaviours (see Table 4) aligned well with their current practice, underlying philosophy and the messages which they provide at other reviews.

Prac-WS4: "It has to come with their own life and the way they are and how is that going to integrate into to their lifestyle so they can make the changes"

Prac-WS1: "it because part of your flow of conversation rather than being told what to do. We talk about responsive feeding, we talk about responsive parenting. That word responsive comes in, so if we respond to their communication and early communication cues..."

There were also substantial differences across parents in which responsive behaviours they felt they needed/wanted to try to do more frequently indicating the need for a tailored approach for individual families. It was also important that any goal was perceived to be focussed and manageable.

Page $7 / 28$ 
Prac-WS4: "But it's about choosing one or two things and not too many things...I think giving them too much and bombarding them with too many things..."

Prac-WS1: "it's something they already do, and you're not asking them to do too much. They're not overwhelmed."

Contexts

Importantly, jumping too quickly to a specific context within which to practise these behaviours, risked alienating families. For example, when considering shared book-reading interventions families reported multiple ways in which this context could cause problems. This included parent/caregivers' perception that it suggested that they might not know book reading was a good idea, which felt patronising, or that they did not do enough book reading, which felt judgemental.

P-CWS1: "I'd be quite offended because I read a lot with my kids. We had this and they said, "Mum, you need to read with them." I read with them quite a lot. I do at least four books on a night .... Then they're saying, "Read with them. That's why he doesn't, you just have to read.... Yes, like it's our fault"

Furthermore, if book reading felt too difficult for the parent/carer either because the child wasn't ready or they themselves had some literacy difficulties this would likely feel too difficult and that it was setting them up to fail.

P-C-WS1: "Everything needs to be the way Danny likes. If I want to read a book to Danny, no, because he wants another book. If you're reading a book to Danny, he's like, "That's enough." He has enough with the book so it's just like...I don't want to be shouting all the time, "Danny Sit down, Danny." I'm like, "You know what? I'm just going to let Danny when he wants it," because I don't want to frustrate him"

P-C-WS1: "So to be honest, I'm not very good at reading books but my husband has a little bit more patience with the language because it's not my language so for me to read, I need to take... a lot of times."

Whilst other parents would very much welcome support with how to share books with their child

P-C-WS2: "I'm not so creative so maybe if we got a sheet with questions on it, that would help a bit more"

It was clear that different families needed and preferred different contexts to practice the chosen intervention behaviours

P-C-WS5: "I just built it into my day all the time really at the moment, when we had a moment...I just worked it in wherever we were."

"On the flip side, for me, having multiple children I wouldn't be able to work it into my daily because it's just mental sometimes.... but for me, this would be brilliant because I would go, "Actually yes, I do need to find a time in my day to focus and that will be my time. That will be when the others are in the bath, dad is bathing them. He can bath Ella and Jack and I will sit on the sofa with Archie."

Prac-WS4: "I think it's the time when they are together that is the critical time. It's making the most of that together time"

Techniques

In terms of intervention techniques extracted from previous research and discussed in the workshops (Table 4), most were felt to be acceptable if their implementation could be adjusted to the particular family's context, if explained appropriately, and if delivered in the context of a relationship of trust between the parent/caregiver and the practitioner. The exceptions (techniques which were considered not acceptable) included the parent/caregiver being videoed by the practitioner, the use of a 'language fit bit' which records how much the parent says to the child and gives a daily report, and teaching another family member how to be a responsive communicator. The former two bringing with them a power dynamic which was not welcomed by many families and a sense of being 'surveilled' and the latter raising significant difficulties with respect to family dynamics and difference of opinion as to how best to parent between partners and across generations.

\section{Barriers and Enablers,}

The work above identified the target behaviour for the intervention: parents/caregivers increasing the frequency of use of one or more of set of responsive interaction behaviors. The barriers and enablers to the use of responsive interaction language promoting behaviours in the home identified in Stage 4 were synthesised and summarised. They are presented in Table 6 and are expressed positively, as enablers. Barriers identified were the absence of or difficulties with these factors.

Intervention functions and policy categories

The main relevant intervention functions identified are also listed in Table 6 and were Training, Enablement, Modelling, Persuasion. The main policy categories (i.e. platform/mechanisms for delivery) are also identified.

Key intervention characteristics necessary for success 
The findings above suggest that both the targeted behaviour and the context within which the family will choose to practice it need to be tailored to the individual family's context and preferences for them to engage with the intervention. Without this tailoring there is a risk of an intervention not being manageable for the family and also of making them feel judged, patronised and/or set up to fail.

\section{The importance of practitioners' language and communication}

It is difficult to overstate the importance of the specific language used by practitioners to talk about children's difficulties, and what parents/caregivers could do to help support their child. Indeed it appeared that no behaviour or context was universally unacceptable as long as the language used avoided implications of blame and judgement and invited the parent/caregiver in as an equal in a process of shared decision-making and goal setting. In this way the appropriate target behaviour and context for the specific family can be agreed.

If not carefully presented, advice can elicit strong negative feelings

P-C WS3 : "might have thrown something at her to be honest"

P-C WS3: "you've done everything and you've read every book, every audio book and every study you can find online and someone says, "Have you tried talking to your child?" you just go, "I'm either going to breathe or lose it so I'm just going to go."

Experienced and skilled practitioners invite parent/caregivers to express preferences, try new behaviours and feedback and problem solve together.

Prac-WS7: "it's very much like they feel that you're going in there to tell them they're doing it wrong. It's not about that. It's about them learning the best way for them to do it themselves, isn't it really."

P-C-WS3: I think if she'd said, "I'm sure you're doing a brilliant job but here's a couple of things you might not have thought about. You could just have a look at this list, it might give you a couple of pointers," rather than, "Right, well this is what you've got to be doing to make your child speak. Do you speak to your child?"

P-C-WS3: "I think a dialogue rather than just being told. A dialogue is good"

It is vital to note that if the necessary trust and therapeutic alliance are not built at this stage then continued engagement with the intervention and therefore its success are extremely unlikely.

The importance of modelling

The important role of modelling responsive interaction by the practitioner with the child attending the review was identified by both practitioners and parents. And seem to fulfil a number of functions:

Demonstrating the behaviour in a non-judgemental non-threatening manner

P-C-WS3: Well I found it useful being shown, not being dictated to but being shown and not in, "I'm now going to show you how to talk to your child," but more just doing it naturally. You think, "Oh." I found that really useful........ I think when you're being told this is what you've got to do but when you see it and you see the way the child engages with it, you see how it works, whereas when you're just being told, "Do this, do this," I don't know, you're butting your head against it a bit and you're feeling a bit just shouted at.

Demonstrating the value of specific responsive interaction behaviours and the potential for the child to engage and benefit from those behaviours

Prac-WS7: "We model a lot of those kind of behaviours in the visit with the parents themselves but also with the children and then they see the child responding. Then they're building their confidence up to do that themselves as well."

Prac-WS7: "I've had that opportunity to get down on the floor and just model. I can see the difference."

P-C-WS3: But I think what was an amazing light bulb moment for me is when I saw the speech and language person speaking to Gemma, engaging and doing things and she was engaging back. It was amazing, "Oh, that happened."

Promoting the parent/caregiver's trust in the practitioner

This emerged through a number of mechanisms: demonstrating skills in engaging with their child, ensuring any advice given was informed by the individual child's temperament and developmental level and needs, and problem solving together about how to support the individual child.

The importance of alliance and trust between parent/caregiver and practitioner

As identified with respect to the importance of practitioner language, relationships of trust between practitioner and parent/caregiver were vital. Demonstrating interest, engagement, and expertise in interaction with the child at the review, also facilitated trust. As does a communication style

Page 9/28 
which invites partnership, dialogue and shared decision-making. An additional factor which facilitated alliance and trust was continuity of support with the same practitioner supporting the family over an extended period of time.

P-C-WS5: "because the number of times I've told my daughter's story"

Continuity was also seen as being important in supporting practitioners to make correct judgements as to the barriers and enablers which might exist for a family's ability to engage in responsive interaction and so to choose the level of support required.

The importance of attractive and motivating resources

The number of information sources and media which compete for parents' attention was mentioned a number of times. Practitioners identified the need therefore to design any messaging and intervention resources in a way which would capture the attention of parents and motivate them to engage.

\section{The importance of inclusiveness and accessibility}

Practitioners emphasised that any resources developed must be accessible and inclusive in a number of ways. They must

- be 'relatable' and represent the range of families served by HV teams in England

- require minimal literacy levels

- be readily adapted to languages other than English

- designed to take account of the range of digital inequalities

Practitioners commented on how effective they found a number of visual resources they use in other aspects of their practice. These included the use of video, attractive visual resources, 'cue cards', and visual reminders.

\section{The importance of fit with current services}

It was clear from discussions that the intervention model would need to fit into current service provision both in terms of HV team models of care, early childhood education and care provision and onward referral pathways for it to be practicable and acceptable.

\section{The Proposed Intervention.}

The proposed intervention aims to empower families to act to support their child as soon as the risk of SLCN is identified. The opportunity for parents/caregivers to be proactive and to feel they have agency in being able to support their child was important to families. This was reported to reduce their sense of helplessness and anxiety and has been shown to be vital for the development and maintenance of family engagement for any subsequent interventions [36]. It also aims to ensure all children and families receive tailored guidance to ensure equity of access to current best evidence regarding how to support their child's language development. The intervention does not replace local SLCN pathways but rather is designed to become coordinated with and integrated into them. It also does not replace referral to Speech and Language Therapy support. It is essential that children continue to be referred for support by SLTs and other professionals where they meet local criteria for referral and receive enhanced support in their early years settings as appropriate.

\section{The intervention model and its components}

The overall goal of the intervention is to increase parents/ caregivers' use of specific responsive interaction behaviours for 10 - 15 minutes per day in a specific context, which suits the family's resources and constraints and is part of their usual daily routine.

All families receive one of three levels of support and links to a universal media and social media campaign (i.e. resources already published or under development by the Best Start in Life program: 'Hungry Little Minds' [73] and 'Tiny Happy People'[74]). Two optional additional support packages may also be offered. Which level families receive and whether or not the optional additional support is offered is determined by the outcome from the ELIM-I measure (developed as part of this study and reported elsewhere) and also practitioner judgement as to the assets and challenges for the family and the barriers and enablers to accessing the intervention: a judgement which is guided by resources and training based on the COM-B model and Theoretical Domains Frameworks $[42,43]$ (see below).

\section{Level 1: Children with no identified risk}

We recommend that all families are signposted to available resources, which provide guidance as to how to support children's language development. We recommend the framing of this review as a time to talk about setting the foundations for the child's learning aligning with the Healthy Child Programme and the PHE priority for the Best Start in Life [15] and the HCP modernisation programme [75].

The universal provision of accessible information based on current knowledge of child language at this review is important to ensure all children reach their full potential. Parent/caregivers' perception of the value of the $2-2 \frac{1}{2}$ year review and their subsequent engagement with services is partly 
influenced by whether they learn something new at that appointment [23]. Importantly, we know that trajectories of language development can be unstable and unpredictable between 2 and 4 years of age and some children who appear to be developing well at 2 years may develop language difficulties later [23]. By ensuring all families are provided with appropriate resources to support them to provide an enriching language environment we therefore provide a 'safety net' for those who may not be identified at this review. Taking a universal rather than targeted approach brings an additional advantage. Targeted selective approaches identify particular groups who are more likely than others to develop a particular condition and offer the intervention to them. In the case of language interventions, this is usually families living with social disadvantage. Such approaches carry the risk of unintentional stigmatisation and consequential disengagement of targeted groups [76]. This can be avoided where families see that the support is universally offered albeit with varying intensity according to need.

Level 2: Children with identified risk - self-directed approach

This level of support is for children identified as being at risk of SLCN using the ELIM and where practitioners judge there are few barriers to the targeted behaviour change. Where barriers do exist, the practitioner judges they mainly relate to the Capabilities category of the $\underline{\mathbf{C}} \mathrm{OM}$-B model (green shading Table 7). If the child meets the criteria for SLT referral for the local pathway then this should be actioned in addition to the following steps:

- Practitioners discuss the need to support their child's language development and the nature of responsive interaction. Language is carefully chosen which promotes the building of trust and engagement and avoids implications of blame or judgement (see materials below).

- Applying principles of shared decision making and strategies to promote trust and engagement, practitioners support families to

- choose a responsive interaction behaviour which they would like to try to do more often

- identify the context and times in the day when they will be able to try this for 10 - 15 minutes - their 'Together Time'.

- record their chosen goal and 'Together Time'

- Discuss their preferred method for being reminded to try this every day - e.g. using a paper diary, a reminder on their phone, a text message from an automated texting system etc.

- Discuss their preferred option for reflecting regularly on how things are going - e.g. using a paper diary, making audio recorded notes on their phone, texting their HV team.

- Engage with modelling, review and reflection activities - e.g. encourage families to look on the 'Tiny Happy People' website for example videos of their chosen goals and to note what the parent/caregiver on those videos did well to support their child and/or to think of other things they could have done to increase their responsiveness.

- Engage with motivational materials - provide a list of web resources which the parent/caregiver can explore which provide motivational information about why responsive interaction is so important and modelling that it can be a fun way to connect with their child. If this feels like too much information for the family, consider sending a link to each web resource weekly through an automated texting system.

- The family then independently follow the programme over 2 - 3 months.

- Review - after an agreed period contact the family to ask if they wish to meet with the practitioner to choose a new goal, troubleshoot any issues with their chosen goal or check on their child's progress.

Level 3: Children with identified risk - coaching approach with additional practitioner support

This pathway is for children identified as potentially being at risk of SLCN using the ELIM and where practitioners judge there are a number of barriers to the targeted behaviour change, particularly in the Motivation and/or Opportunity categories of the CoM-B model (see Table 7). This level uses similar approaches as level 2 above but with additional face-to-face support from the practitioner to tackle motivation and opportunity barriers to change and offer more support for knowledge and skills development where necessary. It is comprised of the following steps

- support families to

- choose a responsive interaction behaviour which they would like to try to do more often

- identify the times in the day when they will be able to try this for 10 - 15 minutes - their 'Together Time'

- record their goal and agree a schedule for visits to work together on this goal.

- At subsequent visits, watch a video with parent/carer showing families trying out the chosen responsive behaviours in the chosen together time. Support reflection about what the families on the video did well and what else they could have tried.

- Model the behaviour with the child - e.g. "shall we try out getting down to his level? I will go first - let's play with his favourite toys and I am going to see if I can get down to his level"

- Encourage the parent to join in the play if they feel comfortable.

- Ask them to reflect on whether they think the chosen behaviour had an effect on how their child interacted

- If the parent/carer was confident enough to try the behaviour ask them how that felt.

- Set a goal for the following week and use a paper diary to record it and set reminders.

- Repeat the above weekly until the parent/carer is confident they are integrating the behaviour in their daily routines 
- Judge whether to continue coaching with a new responsive interaction goal or suggest parent/carer chooses a new goal and works on it independently

- Agree when and how you will check in with the family and review the child's progress

Optional additional support package 1 - access to Early Years settings/social support

An optional additional support package should be offered to families with barriers to behaviour change identified with respect to social opportunities and physical resources necessary for those social opportunities (see Table 6). There was substantial variation across sites as to the accessibility of sources of social support for families, such as parent and toddler groups, and opportunities for early education and care (ECEC). Barriers to access included transport in more rural communities, recent reduction in local authority provision, and confidence to attend, particularly for more socially disadvantaged families, families who had concerns about their child's behaviour and those from minority ethnic groups. The financial support for paid childcare hours is also often difficult for families to navigate with some not being sure of how to access this. These social opportunities are a necessary component for many families to increase their use of the targeted responsive interaction behaviour.

Design and delivery of a support packages to facilitate access to social opportunities will require knowledge regarding local provision and the community assets and resources, which can be mobilised. Action by the practitioner alone is not sufficient if local provision is not accessible to all families. We recommend local co-design of these optional support packages to identify barriers and enable access to parent and toddler groups and early years settings for those families who need it. Co-design work should involve all agencies involved with early years provision, those practitioners who signpost families to them and parents/caregivers.

\section{Optional additional support package 2 - access to age-appropriate books and play materials}

The responsive interaction behaviours targeted in this intervention do not require the provision of any specific play materials or toys. Indeed the goal of the intervention is to support families to integrate responsive interaction into their usual daily routines. In general, no additional toys or children's books are likely to be required. However in some cases, where the family identifies 'playing with toys' or 'sharing books' as their preferred 'together time' and where the family resources are extremely limited, practitioners should consider a support package to address access to toys and books. This may involve support to access toy libraries and the local library. As in the case of ECEC provision, many barriers to access to these resources exist. We recommend local co-design of support packages to identify barriers and enable access to local libraries and toy libraries for families who need this support: those with physical opportunity barriers (see Table 6). In addition, we recommend the development of resources to support families to use everyday materials available at home to develop play and language.

\section{Media and Social Media Campaign}

Existing social media resources from the 'Hungry Little Minds' and 'Tiny Happy People' [33, 74] campaigns align closely to this intervention model. There was, however, a sense of being overwhelmed from some practitioners we spoke to in terms of the range and sheer volume of materials whilst others were not aware of the Tiny Happy People campaign. There was an identified need from practitioners for help to navigate the resources and identify which might be best for which purposes. Both parents and practitioners suggested many families will not seek this information out and, in some cases, may be uncomfortable with a perceived 'educational' tone. The use of a range of social media platforms and active campaigns were suggested as being necessary if these messages are to reach all families of young children. We therefore recommend 'joining up' of this intervention with existing resources and social media campaigns so that the materials developed in this intervention clearly signpost to the high-quality resources being developed.

\section{The steps in intervention delivery.}

- Step 1: Preparation

- Step 2: Decide on the need for intervention and/or onward referral

- Step 3: Choose intervention level

- Step 4: Choose a responsive behaviour to do more often

- Step 5: Choose the context in which to practice the behaviour for $10-15$ mins daily

- Step 6: Deliver tailored support

- Step 7: Offer optional additional support

Step 1 focusses on the preparation, which is necessary for successful shared decision-making and engagement [54, 77]. In order to address power imbalances in the practitioner - parent/caregiver relationship [28] and 'activate' the parent/caregiver [78] preparatory materials are needed which welcome and value the parent/caregivers knowledge about their child, establish the focus of the review [77] and encourage the parent/caregiver to arrive with questions and reflections. Step 2 is essential in mobilising and motivating action by the parent/caregiver and creating practitionerparent/caregiver alliance [36]. Steps 3 - 5 focus on shared decision-making and goal setting. Steps 6 and 7 relate to intervention delivery. Steps 1 - 5 of this model require a holistic approach to both child and parent health and wellbeing and knowledge of the family and so we recommend that the $\mathrm{HV}$ take the lead at these stages. Steps 6 and 7 could involve a more mixed model with skill mix in HV teams or EYPs in early years settings delivering 
the tailored support and/or the optional additional support packages in consultation with the HV team. Level 3 could also involve Speech and Language Therapy services either directly or as advisors to the practitioners delivering the coaching model, depending on the configuration of the local SLCN pathway. This should be negotiated and discussed as part of the local co-design work we recommend above which will be required to develop implementation and sustainability plans for integration into local service delivery context. We recommend that for implementation and maintenance of this programme of work that an integrated team of HVs, SLTs and Early Years leads is convened and maintained to steer its introduction and safeguard its sustainability.

The proposed procedures, content and materials of each intervention stage including recommendations regarding the language to use and methods of presentation, are described in detail in Supplementary Materials 2.

[1] All names in quotes are pseudonyms

\section{Discussion}

This paper presents the findings of a rigorous intervention development methodology to design a universal intervention to promote children's language development to be delivered at the HV $2 \frac{1}{2}$ year review. The study applied the most recent guidance on best practice in intervention design and co-design [34, 35, 37, 45] and was informed by relevant theory with respect to early language development and disorders [32, 47], behaviour change [42], shared decision-making [54, 56], engagement [36], acceptability [42, 52], and implementation [35, 62].

The resulting intervention (ELIM-I) focusses on supporting families to increase their use of responsive interaction behaviours within their daily routines and in contexts tailored to individual family circumstances. The risks of universal interventions widening rather than narrowing inequalities was addressed through consideration of the differing barriers and enablers which may be present for families with a range of assets and challenges. The intervention was therefore designed to offer families a proportionate and tailored response: proportionate in that the intensity of support can increase or decrease depending on the family's needs, and tailored such that the goals and intervention approaches are modified considering the specific barriers and enablers, assets and challenges in each family. The resulting intervention therefore meets a core principle of the modernised Healthy Child Programme - Best Start in Life: 'universal reach and a personalised response'[33]. The importance and potential fragility of alliances between parent/caregiver and practitioner were identified as key and so strategies to engender successful collaborative partnership are also embedded with the ELIM-I design (e.g. shared decision-making, patient activation, collaborative practices).

We found practitioners have an appetite and enthusiasm to promote children's speech, language, and communication development, but were not sure precisely how to deliver support to families. It was also clear that parents/caregivers wanted to be proactive and to have agency in supporting their own children, and to do this as soon as possible. They also wanted specific guidance and resources as to how to do this: parents did not want to watch and wait, they wanted to do all they could to support their children's development. It was very clear was that any such support for the family must not create a delay to access to more specialist Speech and Language Therapy Support for children with more severe difficulties and/or signs of broader developmental concerns. The degree to which SLT and HV services are 'joined up' and have agreed and clear co-working and referral pathways varies substantially across the UK. To deliver ELIM-I and support all children's language development in a given locality it is clear that collaboration between these services is vital.

Analysis of the barriers and enablers to the target behaviour of the intervention (increasing parent/caregiver use of responsive interaction behaviours within daily routines) identified barriers of physical and social opportunity, which are best addressed through access to Early Childhood Education and Care Settings, particularly those which focus on the provision of support for the family as whole. Again, access to these varied across our sites, a picture mirrored across the UK reflecting the reduction in spending on early preventative services in 2010 and the move away from universal provision to more targeted approaches [79]. For this reason, and because of the need for close integration into existing SLCN specialist referral pathways successful delivery of the ELIM-I intervention necessarily requires commissioning and service delivery to be integrated across all the different professionals involved - health visitors and their teams, speech and language therapists and early years practitioners.

Our analysis of the barriers and enablers for families underlined the need for tailored approaches. Families differed significantly as to where the barriers lay to changing the targeted behaviour and in their daily routines and demands on parent/caregiver time. Many published interventions focus on specific behaviours (e.g. shared book reading) or only on the development of knowledge and skills, and do not consider factors of motivation (such as feelings of self-efficacy and confidence to succeed) or social or physical opportunities. Interventions which are not tailored to the specific barriers and enablers present for each are likely not only to be ineffective but also risk alienating families and damaging the potential for engagement with services. A very clear message from our study is that inappropriate advice risks families felling blamed, judged, patronised, or set up to fail. How an intervention is delivered can therefore make or break its success. This intervention therefore draws on theories of shared decision making, engagement and partnership, and strengths-based approaches to increase the potential for success. Although these characteristics are often viewed as core to HV practice [80] our findings suggest families did not always experience them and, as a result, sometimes relationships broke down.

It is difficult to overstate the importance of the language used by practitioners to talk about children's difficulties, and what parents/carers could do to help support their child. Indeed, it appeared that no target intervention behaviour or context was universally unacceptable if the language used avoided implications of blame and judgement and invited the parents/carers in as equals in a process of shared decision making and goal setting. In 
this way the appropriate target behaviour and context for the specific family can be agreed. Inviting parent/caregiver's opinions, acknowledging what they are already doing to help their child and negotiating what works best for them are important ways to encourage a sense of partnership and respect. Care must be taken that discussions with parents/carers do not imply that their interaction style or the time they spend interacting with their child has caused the language difficulties they are experiencing. It can be difficult to understand and to explain that although changing your interaction style can improve your child's language development that your interaction style has not caused their language difficulties.

Our work with parents/carers showed us that demonstrating interest, engagement, and expertise in interaction with the child at the review, facilitates trust in the practitioner. One very practical and powerful way to do this is which was identified several times was for the practitioner to play with the child themselves and, without drawing attention to it, to model responsive interaction with the child.

\section{Strengths and limitations}

This study followed recent guidance for successful intervention development. The iterative methodology served to integrate current best evidence with stakeholder preferences and rich contextual information regarding the context within which the intervention would be delivered. Extensive stakeholder engagement and co-design workshops across a diverse range of sites served to inform the final intervention design. The advent of COVID-19 restrictions in the last phase of data collection meant that our parent/caregiver participant sample was not as diverse, in terms of linguistic and cultural backgrounds as we would have hoped. In the next phase of piloting and implementation of the ELIM-I it will be essential to ensure the views and experiences of a broad demographic of families are solicited.

This study delivered detailed guidelines for the delivery of the ELIM-I intervention. Superficially the ELIM-I intervention is a simple one: supporting parents/caregivers of children at risk of speech language or communication needs to increase their use of responsive interaction behaviours with their child. However, the need for proportionality, tailoring and collaborative partnerships makes successful delivery to the requisite level of fidelity for intervention effectiveness a complex task. Quality improvement, especially across complex, multi-professional, multi-agency systems is rarely easy. Innovation, such as the development of the ELIM-I is only the first step. For successful implementation of this innovation to be achieved further development and scientific evaluation is required.[61, 81]

\section{Next steps}

Embedding health care and educational innovations into routine practice is not straightforward and requires explicit planning. Normalisation process theory suggests that four kinds of work need to occur for an innovation to become 'normalised' practice: coherence work (or sense-making), participation work (or engagement), enacting work (action to enable the intervention to happen), and appraisal work (reflection and monitoring of the benefits and costs)[62].

Our work identified that SLC training for HVs has and is supporting practitioners to do the work of coherence/sense-making and participation/engagement which is required to embed SLC interventions into practices at the $2-2 \frac{1}{2}$ year old review. That is practitioners have an appetite and indeed an enthusiasm to complete this work, see it is aligning with their role and skills and have 'bought in' to delivering interventions to support child language development. However, the next step required for successful and sustainable implementation, that is enacting the intervention remains difficult for practitioners. Our research identified that they remained unsure precisely how to deliver support to families. Whilst the ELIM-I protocol provides further guidance it is, yet to be tested in practice and, in its current form, as guidance rather than as material objects and/or local policy, there are risks with respect to its potential for successful implementation.

Enacting relates to the innovation becoming material practice through practitioners operationalising the innovation into their own specific context: how they find ways to make it work for them and their collaborative team within their specific context. Many potential barriers to implementation of innovations have been identified[81, 82]. Enacting therefore requires effort and support if the innovation is to be sustained and delivered across contexts with the required level of fidelity to the original protocol for it to be effective, feasible, practicable and equitable.

Whilst the ELIM-I provides a protocol for delivery it is untested in practice. Practitioners are likely to require additional support and resources to enable the ELIM-I to be implemented successfully and in a manner which will narrow rather than widen inequalities. Further work is also needed for ELIM-I to be accessible to families from a range of linguistic and cultural backgrounds. For the potential benefits of the ELIM-I to improve children's life chances to be fully realised. We recommend further work to develop and pilot a manualised program with standardised intervention resources and guidance for local implementation and policy development. Strategies to support successful implementation with proven efficacy include the development of simple, evidence-based, accessible, and visually clear and appealing resources, the use of decision support systems, checklists and digital tools, and context specific standardised protocols[83]. Furthermore, multi-professional collaboration and the development of local consensus groups have been shown to improve implementation [84, 85].

The response of services to the COVID-19 pandemic have underlined the diversity in service provision which exists across the country for children in the first 1001 days and the benefits which can be realised when early years settings and HV services collaborate to support vulnerable families [86]. Furthermore, the DfE is ambitious to leverage the skills, knowledge, and capacity of the whole children's workforce to give children the 'Best start in Speech Language and Communication'. To date the ELIM-I development has focussed in the main on HV teams. Whilst the key principles of the ELIM- 
I will readily translate to Early Years settings its implementation must be contextualised. Further work is needed to adapt the ELIM-I for use in early years settings to facilitate inter-agency collaboration.

A fundamental shift for services during the pandemic has been the move to remote support using digital tools. There is an acknowledgement amongst professionals and families of both benefits and harms from this shift. For some families, remote services are welcomed as convenient, lower cost and accessible whilst for others the 'digital divide' make them completely inaccessible. Importantly for families with the highest level of need remote services do not support the necessary development of professional and parent-caregiver trust and alliance for successful support to be delivered [86].

Digital remote delivery therefore will never be a panacea for service delivery to support families of children in the early years. However, within a matrix of differing tailored support, digital delivery offers the potential for convenient and economical delivery for some families, potentially freeing up resource for face-to-face support for those with the greatest need for specialist practitioner support. Development of methods to deliver ELIM-I digitally therefore could bring potential benefits with respect to further tailoring and personalised care, and possible cost savings. In addition, they ensure services are robust to future pandemic or other 'shocks' to services for children and families and have the potential to enable multi-disciplinary collaboration.

\section{Conclusions}

It is possible to develop a universal intervention for use by HVs at the 2-2 1/2 year review to promote children's language development which is acceptable and feasible. For such an intervention to be equitable and to promote engagement and partnership it must be proportionate, varying in intensity of support, tailored, such that goals and intervention approaches address the specific barriers and enablers, assets and challenges in each family, and must address power relationships through shared decision-making, patient activation and strengths-based approaches.

\section{Abbreviations}

HV - Health Visitor

ELIM-I Early Language Identification Measure and Intervention

SLCN - Speech, Language, and Communication Needs

SLC - Speech Language and Communication

COM-B Capability Opportunity Motivation Behavoiur

ASQ-3 Ages and Stages Questionnaire 3

DfE - Department for Education

PHE - Public Health England

HCP - Healthy Child Program

APEASE - Acceptability, Practicability, Efficacy, Affordability, Safety and Equity

PPI - Public, Patient Involvement

R\&D - Research and Development

REC - Research Ethics Committee

CNN- Community Nursery Nurses

SLT - Speech and Language Therapist

ECEC - Early Childhood Education and Care

\section{Declarations}

Ethics approval and consent to participate

All relevant details about the project were submitted to the West Midlands - Black Country NHS Research Ethics Committee (REC) and a favourable ethical opinion was received on 7th of May 2019 REC reference 19/WM/0114 project \# 261205. R\&D management approvals were then received from the five sites involved in the study. Participants gave fully informed consent before each workshop/data collection episode.

Page $15 / 28$ 
Not applicable

Availability of data and materials

The datasets generated and/or analysed during the current study are not publicly available due to the ethical approvals in place making data sharing non-permissible. Participants did not give permission for data sharing. All qualitative data collection materials are available from the first corresponding author on reasonable request.

Competing interests

The author(s) declare(s) that they have no competing interests

Funding

The project was funded by the UK's Department for Education in conjunction with Public Health England

Authors' contributions

Cristina McKean led the study, designed the methodology, and data collection materials and conducted all aspects of the data collection and analysis. She wrote the first draft of the paper and created the final version for submission after revisions and suggestions from co-authors.

Rose Watson coordinated data collection processes and conducted data collection processes acted as facilitator or observer on a number of the data collection events and participated in interpretive reflections that informed the analyses. She also contributed to the writing of the paper.

Caitlin Holme acted as a facilitator for data collection, and participated in interpretive reflections that informed the analyses. She also contributed to the writing of the paper

Jenna Charlton coordinated ethical approval processes, conducted PPI workshops which informed data collection and interpretation, and participant recruitment. She participated in interpretive reflections that informed the analyses. She also contributed to the writing of the paper.

Vicky Gilroy conducted PPI workshops which informed data collection and interpretation, and participant recruitment. She participated in interpretive reflections that informed the analyses. She also contributed to the writing of the paper.

James Law, was PI on the broader project of which the intervention development component described here was a part. He was involved in the conception and design of the study and data interpretation. He also contributed to the writing of the paper.

Sue Roulstone was a co-applicant on the research programme, acted as facilitator or observer on a number of the data collection events and participated in interpretive relfections that informed the analyses. She also contributed to the writing of the paper.

\section{Acknowledgements}

We would like to express sincere thanks to all the practitioners and parents who gave their time, expertise, and insights in the workshop and codesign activities. The team also wish to acknowledge the role of Sheena Carr and Renvia Mason and colleagues at Public Health England and The Department for Education for their feedback on the original report.

\section{References}

1. Shonkoff, J.P., Protecting brains, not simply stimulating minds. Science, 2011. 333: p. 982-983.

2. Heckman, J.J., Skill formation and the economics of investing in disadvantaged children. Science, 2006. 312(5782): p. $1900-1902$.

3. Law, J., J. Charlton, and K. Asmussen, Language as a Child Wellbeing Indicator. 2017, Early Intervention Foundation: London.

4. Snowling, M.J., et al., Psychosocial outcomes at 15 years of children with a preschool history of speech-language impairment. Journal of Child Psychology and Psychiatry, 2006. 47(8): p. 759-765.

5. Law, J., et al., Modeling developmental language difficulties from school entry into adulthood: Literacy, mental health, and employment outcomes. Journal of Speech Language and Hearing Research, 2009. 52(6): p. 1401-1416.

6. Schoon, I., et al., Children's language ability and psychosocial development: A 29-year follow-up study. Pediatrics, 2009. 126(1).

7. DeWalt, D.A. and A. Hink, Health literacy and child health outcomes: A systematic review of the literature. Pediatrics, 2009. 124(SUPPL. 3): p. S265-S274.

8. Törnqvist, M.C., et al., Adult people with language impairment and their life situation. Communication Disorders Quarterly, 2009. 30(4): p. 237254.

Page $16 / 28$ 
9. Norbury, C.F., et al., The impact of nonverbal ability on prevalence and clinical presentation of language disorder: evidence from a population study. Journal of Child Psychology and Psychiatry, 2016.

10. Law, J., K. McBean, and R. Rush, Communication skills in a population of primary school-aged children raised in an area of pronounced social disadvantage. International Journal of Language and Communication Disorders, 2011. 46(6): p. 657-664.

11. Field, F., The Foundation Years: preventing poor children becoming poor adults. 2010, Cabinet Office: London.

12. Shonkoff, J.P., Science, Policy, and the Young Developing Child: Closing the gap between what we know and what we do. . 2007, Chicago III: Ounce of Prevention Fund.

13. Bercow, J., Bercow review of services for children and young people (0-19) with speech, language and communication needs, DCSF, Editor. 2008, DCSF Publications: Nottingham.

14. Law, J., et al., Child language in a public health context. 2017, Melbourne: Centre of Research Excellence in Child Language.

15. Public Health England. PHE Strategy 2020-2025. 2019, Available from: https://www.gov.uk/government/publications/phe-strategy-2020-to-2025.

16. Department of Health. The Healthy Child Programme: Pregnancy and the first five years of life. 2009, Available from: https://www.gov.uk/government/publications/healthy-child-programme-pregnancy-and-the-first-5-years-of-life.

17. Public Health England. Best start in life and beyond: Improving public health outcomes for children, young people and families Guidance to support the commissioning of the Healthy Child Programme 0-19: Health visiting and school nursing services. 2018, Available from: https://www.gov.uk/government/publications/healthy-child-programme-0-to-19-health-visitor-and-school-nurse-commissioning.

18. Public Health England. Early Years High Impact Area 6: Health, wellbeing and development of the child aged 2: Ready to learn, narrowing the 'word gap'. . 2018, Available from: https://www.gov.uk/government/publications/commissioning-of-public-health-services-for-children.

19. Squires, J. and D. Bricker, Squires, J., \& Bricker, D. (2009). Ages \& Stages Questionnaires ${ }^{\circledR}$, Third Edition (ASQ $\left.{ }^{\circledR}-3\right)$ : A Parent-Completed Child Monitoring System. Baltimore: Paul H. Brookes Publishing Co., Inc. 2009, Baltimore: Paul H. Brookes Publishing Co., Inc.

20. Department for Education. Multi-million investment to support children's early communication skills. 2018, Available from: https://www.gov.uk/government/news/multi-million-investment-to-support-childrens-early-communication-skills.

21. Public Health England, Early language identification measure and intervention: Guidance Handbook. 2020, Department for Education and Department of Health and Social Care: London.

22. Public Health England. Identifying and supporting children's early language needs: summary report. 2020, Available from: https://assets.publishing.service.gov.uk/government/uploads/system/uploads/attachment_data/file/939833/ELIM_Summary_report_December2020.pdf.

23. Law, J., et al., Identifying and Supporting Children's Early Language Needs. 2020, Newcastle University: Newcastle upon Tyne.

24. McKean, C., et al., Levers for language growth: Characteristics and predictors of language trajectories between 4 and 7 years. PLoS ONE, 2015. 10(8): p. e0134251.

25. Law, J., et al., Early Language Development: Needs, provision, and intervention for preschool children from socio-economically disadvantage backgrounds. 2017, London: Institute of Education.

26. Law, J., et al., Parent-child reading to improve language development and school readiness: A systematic review and meta-analysis. 2018: Newcastle University and Queen Margaret University.

27. Roberts, M.Y. and A.P. Kaiser, The effectiveness of parent-implemented language interventions: A meta-analysis. American Journal of SpeechLanguage Pathology, 2011. 20(3): p. 180-199.

28. Roberts, M.Y. and A.P. Kaiser, Early Intervention for Toddlers With Language Delays: A Randomized Controlled Trial. Pediatrics, 2015: p. peds.2014-2134.

29. McGillion, M., et al., A randomised controlled trial to test the effect of promoting caregiver contingent talk on language development in infants from diverse socioeconomic status backgrounds. Journal of Child Psychology and Psychiatry and Allied Disciplines, 2017. 58(10): p. 1122-1131.

30. Law, J., Z. Garrett, and C. Nye, The efficacy of treatment for children with developmental speech and language delay/disorder: A meta-analysis. Journal of Speech, Language, and Hearing Research, 2004. 47(4): p. 924-943.

31. Levickis, P., et al., Associations between maternal responsive linguistic input and child language performance at age 4 in a community-based sample of slow-to-talk toddlers. Child: Care, Health and Development, 2018. 44(5): p. 776-783.

32. Levickis, P., et al., Maternal Behaviors Promoting Language Acquisition in Slow-to-Talk Toddlers: Prospective Community-based Study. Journal of Developmental \& Behavioral Pediatrics 2014. 35(4): p. 274-281.

33. NHS England, Best Start in Life. 2020.

34. Craig, P., et al., Developing and evaluating complex interventions: new guidance. 2008, Medical Research Council.

35. O'Cathain, A., et al., Guidance on how to develop complex interventions to improve health and healthcare. BMJ Open, 2019. 9(8).

36. Melvin, K., C. Meyer, and N. Scarinci, What does "engagement" mean in early speech pathology intervention? A qualitative systematised review. Disabil Rehabil, 2019: p. 1-14.

Page $17 / 28$ 
37. Duncan, E., et al., Guidance for reporting intervention development studies in health research (GUIDED): an evidence-based consensus study. BMJ Open, 2020. 10(ee033516).

38. Smith, K.E., C. Bambra, and S.E. Hill, Health Inequalities: Critical Perspectives. 2015, Oxford: Oxford University Press.

39. Marulis, L.M. and S.B. Neuman, How Vocabulary Interventions Affect Young Children at Risk: A Meta-Analytic Review. Journal of Research on Educational Effectiveness, 2013. 6(3): p. 223-262.

40. Becker, B., Social disparities in children's vocabulary in early childhood. Does pre-school education help to close the gap? British Journal of Sociology, 2011. 62(1): p. 69-88.

41. Marmot, M., et al., Strategic review of health inequalities in England post - 2010: Fair society healthy lives: the Marmot review. 2010, London: UCL.

42. Michie, S., L. Atkins, and R. West, The behaviour change wheel: a guide to designing interventions. 2014, Surrey: England: Silverback Publishing.

43. Cane, J., D. O'Connor, and S. Michie, Validation of the theoretical domains framework for use in behaviour change and implementation research. Implementation Science, 2012. 7(1): p. 37.

44. Carey, G., B. Crammond, and E. De Leeuw, Towards health equity: a framework for the application of proportionate universalism. International Journal for Equity in Health, 2015. 14(1): p. 81.

45. O'Brien, N., et al., Integrating evidence from systematic reviews, qualitative research, and expert knowledge using co-design techniques to develop a web-based intervention for people in the retirement transition. Journal of Medical Internet Research, 2016. 18(8): p. e210.

46. Holme, C., et al., Parental experiences and perspectives of the $2-2 \frac{1}{2}$ year developmental review process for identifying speech, language and communication needs under review.

47. Tomasello, M., Origins of human communications. 2008, London, England: MIT Press.

48. Tomasello, M., Acquiring linguistic constructions, in Handbook of Child Psychology, D. Kuhn and R. Siegler, Editors. 2006, Wiley: New York. p. 225298.

49. Tomasello, M., First steps toward a usage-based theory of language acquisition. Cognitive Linguistics, 2000. 11(1-2): p. 61-82.

50. Rowe, M.L. and C.E. Snow, Analyzing input quality along three dimensions: interactive, linguistic, and conceptual. J Child Lang, 2020. 47(1): p. 521.

51. Donnellan, E., et al., Infants' intentionally communicative vocalizations elicit responses from caregivers and are the best predictors of the transition to language: A longitudinal investigation of infants' vocalizations, gestures and word production. Developmental Science, 2020. 23(1): p. e12843.

52. Sekhon, M., M. Cartwright, and J.J. Francis, Acceptability of healthcare interventions: An overview of reviews and development of a theoretical framework. BMC Health Services Research, 2017. 17(1).

53. Bekker, H., et al., Informed decision making: an annotated bibliography and systematic review. Health Technology Assessments, 1999. 3(1): p. 1156.

54. Joseph-Williams, N., A. Edwards, and G. Elwyn, Power imbalance prevents shared decision making. BMJ : British Medical Journal, 2014. 348: p. g3178.

55. Stacey, D., et al., Decision aids for people facing health treatment or screening decisions. Cochrane Database of Systematic Reviews, 2017(4).

56. Elwyn, G., et al., Shared Decision Making: A Model for Clinical Practice. Journal of General Internal Medicine, 2012. 27(10): p. $1361-1367$.

57. de Silva, D., Evidence: helping people help themselves. 2011: The Health Foundation.

58. de Silva, D., Helping people share decision making. 2012: The Health Foundation.

59. Légaré, F., et al., Interventions for improving the adoption of shared decision making by healthcare professionals. Cochrane Database Syst Rev, 2014(9): p. Cd006732.

60. Légaré, F., et al., Interventions for improving the adoption of shared decision making by healthcare professionals. Cochrane Database Syst Rev, 2010(5): p. Cd006732.

61. May, C. and T. Finch, Implementing, Embedding, and Integrating Practices: An Outline of Normalization Process Theory. Sociology, 2009. 43(3): p. 535-554.

62. Murray, E., et al., Normalisation process theory: a framework for developing, evaluating and implementing complex interventions. . BMC Medicine, 2010. 8(1): p. 63.

63. CRE-CL and CfCCH, Every Toddler Talking (Phase 1) Final report. 2015, MCRI: Melbourne.

64. Axford, N., et al., The best start at home, in Early Intervention Foundation Evidence. 2015, Early Intervention Foundation: London.

65. Asmussen, K., et al., Foundations for life: what works to support parent child interaciton in the early years. Evidence. 2016: Early Intervention Foundation.

66. Levickis, P., et al., A review of interventions to promote language development in early childhood, in Language Development: Individual Differences in a Social Context, J. Law, C. McKean, and S. Reilly, Editors. in press, Cambridge University Press: Cambridge.

67. Early Intervention Foundation. The EIF guidebook. [cited 2019, Available from: https://guidebook.eif.org.uk/.

68. Pruitt, J. and T. Adlin, The persona lifecycle: keeping people in mind throughout product design. 2006, Amsterdam: Elsevier.

Page 18/28 
69. Morgan, L., et al., 'It depends': Characterizing speech and language therapy for preschool children with developmental speech and language disorders. International Journal of Language \& Communication Disorders, 2019. 54(6): p. 954-970.

70. Christensen, D., C.L. Taylor, and S.R. Zubrick, Patterns of Multiple Risk Exposures for Low Receptive Vocabulary Growth 4-8 Years in the Longitudinal Study of Australian Children. PLoS One, 2017. 12(1): p. e0168804.

71. Cane, J., D. O'Connor, and S. Michie, Validation of the theoretical domains framework for use in behaviour change and implementation research. Implementation Science, 2012. 7(37).

72. Atkins, L., et al., A guide to using the Theoretical Domains Framework of behaviour change to investigate implementation problems. Implementation Science, 2017. 12(1): p. 77.

73. Best Start in Life. Hungry Little Minds. 2019, Available from: https://hungrylittleminds.campaign.gov.uk/

74. BBC, Tiny Happy People. 2019.

75. Public Health England. Healthy child programme 0 to 19: health visitor and school nurse commissioning. 2021, Available from: https://www.gov.uk/government/publications/healthy-child-programme-0-to-19-health-visitor-and-school-nursecommissioning\#: :text=|t\%20focuses\%20on\%20the\%20contribution,programme\%20for\%20prevention\%20and\%20support.

76. Guttman, N. and C.T. Salmon, Guilt, Fear, Stigma and Knowledge Gaps: Ethical Issues in Public Health Communication Interventions. Bioethics, 2004. 18(6): p. 531-552.

77. Levickis, P., et al., Expectations and experiences of parents taking part in parent-child interaction programmes to promote child language: a qualitative interview study. International Journal of Language \& Communication Disorders, 2020. 55(4): p. 603-617.

78. Hibbard, J. and H. Gilburt, Supporting people to manage their health: An introduction to patient activation. 2014, London: The Kings Fund.

79. Bouchal, P. and E. Norris, Implementing Sure Start children's centres. 2014, London: Institute for Government.

80. R, A., S. A, and C. H., Working in partnership: the application of shared decision-making to health visitor practice. Journal of Clinical Nursing, 2017. 26(1): p. 215-224.

81. Fischer, F., et al., Barriers and Strategies in Guideline Implementation-A Scoping Review. Healthcare, 2016. 29(3): p. 36.

82. Francke, A.L., et al., Factors influencing the implementation of clinical guidelines for health care professionals: A systematic meta-review. BMC Medical Informed Decision Making 2008.

83. Grol, R.P., et al., Planning and studying improvement in patient care: the use of theoretical perspectives. Milbank Quarterly, 2007. 85(1): p. 93-138.

84. Lugtenberg, M., et al., Why don't physicians adhere to guideline recommendations in practice? An analysis of barriers among dutch general practitioners. Implementation Science, 2009.

85. Mourad, S.M., et al., A multi-faceted strategy to improve the use of national fertility guidelines, a cluster-randomized controlled trial. Human Reproduction, 2011. 26: p. 817-826.

86. Reed, J. and N. Parish, Working for babies: lockdown lessons from local systems. 2021: First 1001 days Movement.

\section{Tables}

Table. 1. Principles and actions in complex intervention development (O'Cathain et al., 2019)

\begin{tabular}{|ll|}
\hline Principles & Actions to consider \\
\hline dynamic & Plan the process \\
iterative & Involve Stakeholders \\
open to change & Bring together a team \\
look towards evaluation & Review published evidence \\
& Araw on existing theory \\
& Undertake primary data collection \\
& Understand context \\
& Attend to future implementation \\
& Design and refine \\
\hline
\end{tabular}

Table 2. Stakeholder workshops and participant characteristics 


\begin{tabular}{|c|c|c|c|c|c|}
\hline Stage & Site & Group & $\mathrm{N}$ & Professional groups & Code \\
\hline \multirow[t]{7}{*}{3} & 1 & Parents/caregivers & 2 & & P-C-WS1 \\
\hline & & Practitioners & 3 & $2 \mathrm{HVs}, 1$ Student HV & Prac-WS1 \\
\hline & & Practitioners & 2 & $1 \mathrm{HV}, 1$ Student HV & Prac-WS2 \\
\hline & 2 & Parents/caregivers & 2 & & P-C-WS2 \\
\hline & & Practitioners & 5 & $3 \mathrm{HV}, 2$ SLTs & Prac-WS3 \\
\hline & 3 & Parents/caregivers & 2 & & P-C-WS3 \\
\hline & & Practitioners & 6 & 2 HVs, 2 SLTs, 2 SLTAs & Prac-WS4 \\
\hline \multirow[t]{6}{*}{5} & 1 & Parents/caregivers & 1 & & P-C-WS4 \\
\hline & & Practitioners & 10 & 5 HVs, 2 CNNs, 2 SLTs & Prac-WS5 \\
\hline & 3 & Parents/caregivers & 2 & & P-C-WS5 \\
\hline & & Practitioners & 8 & 4 CNNs, 2 SLTs, 2 SLTAs & Prac-WS6 \\
\hline & 4 & Practitioners & 3 & $3 \mathrm{HVs}$ & Prac-WS7 \\
\hline & 5 & Practitioners & 9 & $5 \mathrm{HVs}, 1$ Family Nurse, $2 \mathrm{CNNs}$, 1 Student Nurse & Prac-WS8 \\
\hline \multicolumn{6}{|c|}{$\begin{array}{l}\text { Key: HV = Health Visitor, CNN = Community Nursery Nurse, SLT = Speech and Language Therapist, SLTA = Speech and Language Therapy } \\
\text { Assistant, Prac = Practitioner, P-C = Parent } / \text { caregiver, WS = Workshop }\end{array}$} \\
\hline
\end{tabular}

Table 3: Workshop descriptors of the behaviours targeted and intervention techniques used in the research literature 
Intervention type

Shared/ dialogic bookreading
Behaviour(s) targeted by intervention

Share an age appropriate book with your child for $10-15$ minutes per day for 5 or more times per week. While sharing the book

1. Ask open questions like 'where, who what........'

2. Avoid questions where your child might answer 'yes' or 'no' or just point

3. When your child answers - follow up with another question

4. Follow the child's interests in the book

5. Praise them for good answers and ideas

6. Expand what the child says - so if they say 'ball' you say 'yes - a big ball'

Responsive/contingent interaction

Focussed stimulation

1) Work with a practitioner to choose a language goal for your child - this can be target sentences or target words.

2) Identify activities in the day to use that target sentence or target words with your child

3) Set up play activities to encourage your child to use the target words or sentences.
Intervention Techniques

- You are given gifts of age appropriate books

- You watch the Health Visitor show you how to share the book using the recommended behaviours

-While you share the book using the recommended behaviours you are videoed and then you and the Health Visitor look at the video together and see what you might change

- You attend a group at a community centre or library to work with other parents to learn the recommended techniques for book sharing - you watch videos of other parents sharing books with their child and discuss what they might change

- You are phoned weekly to see how you are doing

- You are given a leaflet describing the techniques to use when sharing books with your child

- You are asked to keep a diary of when, where and for how long you share a book with your child

- The Health visitor explains to you how shared book reading benefits your child

- You are given gifts of age appropriate toys which will help you to follow their lead You watch the Health Visitor show you how to play with your child using the recommended 'responsive communication' behaviours

-While you play with your child using the recommended 'responsive communication' behaviours you are videoed and then you and the Health Visitor look at the video together and see what you might change

- You attend a group at a community centre or library to work with other parents to learn the recommended techniques for 'responsive communication' - you watch videos of other parents playing with their child and discuss what they might change

- You are phoned weekly to see how you are doing

- You are given a leaflet describing the responsive communication behaviours to use when playing or in everyday activities with your child

- You are asked to set aside 15 minutes per day to practice this responsive communication and to keep a diary of when, where and for how long you manage to do this

- The Health visitor explains to you how shared book reading benefits your child

- You have a wristband - like a fit bit - which records how much you say to your child and you get a daily report

- You and the Health Visitor make a plan together about the best times in the day and activities to practice this responsive communication

- You and the Health Visitor reflect on how things have gone this week and what you might change

- You are given fridge magnets to help you to remember how to be a responsive communicator with your child

- You are asked to teach a close family member how to be a responsive communicator and to support you

- Over the weeks you create a library of you and your child playing and communicating to look back over and share with your family

- You are helped to identify resources in your local community where you can get help and advice, meet other parents and where your child can experience play with other children

- You watch the professional show you how to play with your child using focussed stimulation

- While you play with your child using the recommended 'focussed stimulation' you are videoed and then you and the professional look at the video together and see what you might change

- You attend a group at a community centre or library to work with other parents to learn the recommended techniques for focussed stimulation you problem solve how to create play situations to encourage certain kinds of words and sentences

Page 21/28 
4) Ask your child to follow instructions and copy you saying these words or sentences.
- You are helped to plan games to play with your child to encourage certain kinds of words and sentences

- You agree goals to work on over the next two weeks - choosing games to play and how often to try them

- You are asked to think back and reflect on how well you have done over the past fortnight and think about things you might change

- You receive toys in the post with a newsletter explaining how to play to encourage certain target language structures appropriate for your child's age

Table 4. Descriptions of family 'persona' used to elicit practitioners implicit decision-making processes.

Persona

Sam and Joe have 4 children. The child you are visiting has 2 older brothers and a younger sister aged 4 months. The family live in social housing and receive benefits. Sam works full time in a bar near home. Joe works 2 or 3 hours a week for a cleaning company. Joe and Sam both left school at sixteen. Most of their extended family live nearby. They try to manage their shifts so as not to have any additional childcare and call on family and friends.

Lee has two children under the age of 4, you are visiting the younger child. Lee left school at 16 years, is currently not working and is in receipt of benefits. The family are living in a one-bedroom flat far away from Lee's extended family. You are concerned about Lee's mental health. When you observe the family you feel Lee's response to her children is very inconsistent, sometimes responsive and other times less so.

Alex and Lesley live in an estate of privately-owned houses. Alex works fulltime as a head teacher at the local school and Lesley is currently not working. They have two children, and you are visiting their youngest child who had low birth weight and spent a short time on SCBU. They are worried about their child's behaviour. Her attention seems to flit from one toy to another and she can be hard to manage if she does not get her own way. Lesley seems very distressed when describing day to day life.

Susie is a first-time parent who was pregnant when she left school. She is not in paid work and receives benefits. She lives with her parents in social housing. Her parents are also both long-term unemployed. She has a large community of friends. and family nearby.

Ivory and Chidi have 5 children aged between 1 and 13 years and you are visiting their second youngest child with an interpreter. Both Ivory and Chidi speak very little English and are currently not working. The estate where they live has poor transport links and few community services. You are concerned about Ivory's mental health.

Nehal and Gurpreet both work full time Nehal as a police officer and Gurpreet as an IT technician. You are visiting their first child. They have no extended family nearby and rely on a mix of a childminder and private nursery for childcare.

Table 5. Mapping data to the Theoretical Domains Framework, Intervention Functions and Policy categories 


\begin{tabular}{|c|c|c|c|c|}
\hline COM-B & TDF & Specifics of barriers and enablers of relevance to the domain & $\begin{array}{l}\text { Intervention } \\
\text { Function }\end{array}$ & Policy Categories \\
\hline \multirow[t]{25}{*}{$\begin{array}{l}\text { Reflective } \\
\text { motivation }\end{array}$} & \multirow{3}{*}{$\begin{array}{l}\text { Professional/ } \\
\text { social role and } \\
\text { identity }\end{array}$} & \multirow[t]{3}{*}{ - Social role - parents want to do the best for their child } & Education & \multirow{3}{*}{$\begin{array}{l}\text { Communication/ } \\
\text { Marketing } \\
\text { Service Provision }\end{array}$} \\
\hline & & & Persuasion & \\
\hline & & & Modelling & \\
\hline & \multirow[t]{3}{*}{$\begin{array}{l}\text { Beliefs about } \\
\text { capabilities }\end{array}$} & $\begin{array}{l}\text { - Self-esteem, belief about own capabilities, perceived } \\
\text { competence - e.g. training others }\end{array}$ & Education & \multirow{3}{*}{$\begin{array}{l}\text { Communication/ } \\
\text { Marketing } \\
\text { Service Provision }\end{array}$} \\
\hline & & \multirow{2}{*}{$\begin{array}{l}\text { - Some parents may believe they are "doing it all" - need to be } \\
\text { challenged? }\end{array}$} & fensuastom & \\
\hline & & & Enablement & \\
\hline & \multirow[t]{4}{*}{ Optimism } & \multirow[t]{4}{*}{ - Optimism - self efficacy through video of progress } & Education & \multirow{4}{*}{$\begin{array}{l}\text { Communication/ } \\
\text { Marketing } \\
\text { Service Provision }\end{array}$} \\
\hline & & & Persuasion & \\
\hline & & & Modelling & \\
\hline & & & Enablement & \\
\hline & \multirow[t]{5}{*}{$\begin{array}{l}\text { Beliefs about } \\
\text { consequences }\end{array}$} & $\begin{array}{l}\text { - Believe advantaging children if give them technology whilst } \\
\text { underestimating value of own interactions }\end{array}$ & \multirow{5}{*}{$\begin{array}{l}\text { Education } \\
\text { Persuasion } \\
\text { Modelling }\end{array}$} & \multirow{5}{*}{$\begin{array}{l}\text { Communication/ } \\
\text { Marketing } \\
\text { Service Provision }\end{array}$} \\
\hline & & $\begin{array}{l}\text { - Want to do the best for their child - but need simple } \\
\text { messages explaining benefits of specific behaviours to their } \\
\text { child }\end{array}$ & & \\
\hline & & $\begin{array}{l}\text { - Parent believes child can't do it - sees HV do it and changes } \\
\text { their views }\end{array}$ & & \\
\hline & & - Parent may believe that what they do won't make a difference. & & \\
\hline & & $\begin{array}{l}\text { - Parent may believe watching a story on the television is the } \\
\text { same as sharing a book }\end{array}$ & & \\
\hline & \multirow[t]{5}{*}{ Intentions } & - Develop intentions to do the behavior - agree to try & Education & \multirow{5}{*}{$\begin{array}{l}\text { Communication/ } \\
\text { Marketing } \\
\text { Service Provision }\end{array}$} \\
\hline & & - Maintain stable intentions & Persuasion & \\
\hline & & & Ineentivisation & \\
\hline & & & Goereion & \\
\hline & & & Modelling & \\
\hline & \multirow[t]{5}{*}{ Goals } & $\begin{array}{l}\text { - Set goals - describe and identify concrete time and contexts } \\
\text { to do behaviours }\end{array}$ & Education & \multirow{5}{*}{$\begin{array}{l}\text { Communication/ } \\
\text { Marketing } \\
\text { Service Provision }\end{array}$} \\
\hline & & - Action planning and & 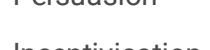 & \\
\hline & & $\begin{array}{l}\text { - Choose goal and time of day and make a very specific time } \\
\text { and context to try something new }\end{array}$ & Goereion & \\
\hline & & \multirow{2}{*}{$\begin{array}{l}\text { - Know that you will be reviewed - have check in a good } \\
\text { motivator }\end{array}$} & Modelling & \\
\hline & & & Enablement & \\
\hline \multirow{10}{*}{$\begin{array}{l}\text { Automatic } \\
\text { motivation }\end{array}$} & \multirow[t]{5}{*}{ Reinforcement } & - e.g. Through video of child's progress & Training & \multirow{5}{*}{$\begin{array}{l}\text { Communication/ } \\
\text { Marketing } \\
\text { Service Provision }\end{array}$} \\
\hline & & - Having a go and seeing it work is best reinforcement & Ineentivisation & \\
\hline & & - Video could reinforce feelings of hopelessness - inability & Goercion & \\
\hline & & - Pleasure gained from sharing 'special toys' & \multirow{2}{*}{$\begin{array}{l}\text { Environmental } \\
\text { restructuring }\end{array}$} & \\
\hline & & $\begin{array}{l}\text { - Books/gifts much more rewarding than info giving leaflet - } \\
\text { more likely to engage }\end{array}$ & & \\
\hline & \multirow[t]{5}{*}{ Emotion } & - Embarrassment/discomfort to try new behavior & Persuasion & \multirow{5}{*}{$\begin{array}{l}\text { Communication/ } \\
\text { Marketing } \\
\text { Service Provision }\end{array}$} \\
\hline & & - Overwhelm & Ineentivisation & \\
\hline & & \multirow[t]{3}{*}{ - Fear of exposure as not having skills themselves } & Eoereion & \\
\hline & & & Modelling & \\
\hline & & & Enablement & \\
\hline
\end{tabular}


Notes: analysis is based on guidance and resources in Michie, S., L. Atkins, and R. West, The behaviour change wheel: a guide to designing interventions. 2014, Surrey: England: Silverback Publishing.. Strike through i.e. Ineentivisation indicates an intervention function identified as relevant to the TDF and barrier/enabler but judged not to be appropriate to the intervention context

Table 6 Enablers identified as needing to be in place to engage in the target behaviour change (increase frequency of responsive interaction behaviour) organised with respect to the COM-B components and the TDF domains.

\begin{tabular}{|c|c|}
\hline $\begin{array}{l}\text { COM-B } \\
\text { component }\end{array}$ & TDF Domain and description of enablers \\
\hline \multirow[t]{10}{*}{ Capability } & Physical skills \\
\hline & Have skills to follow a child's lead in play or share a book \\
\hline & Have literacy skills to share a book \\
\hline & Knowledge \\
\hline & able to choose age appropriate books, toys and activities \\
\hline & know what kinds of questions to ask during book sharing/shared activities and how to follow child's interests \\
\hline & Decision making \\
\hline & Able to decide on what they need to change to achieve their goal \\
\hline & Regulation \\
\hline & Able to monitor their own use of the new behaviour and make and stick to an action plan to do it \\
\hline \multirow[t]{13}{*}{ Motivation } & Belief about capabilities and optimism \\
\hline & Feel they can make the change and increase the use of this behaviour \\
\hline & Feel making the change is worthwhile and that there is scope to increase their responsiveness \\
\hline & Beliefs about consequences \\
\hline & Feel child will engage and so will respond or benefit \\
\hline & $\begin{array}{l}\text { Feel the chosen behaviours are best for the child and other behaviours (e.g. TV viewing) are not equally good - have reason } \\
\text { to change }\end{array}$ \\
\hline & Feel that what they do will make a difference \\
\hline & Intentions and goals \\
\hline & Have definite intention to try to increase their use of the behaviour \\
\hline & Able to set a clear goal and create action plan for implementing it \\
\hline & Emotion \\
\hline & Do not feel Embarrassed at trying new behaviour and/or have fear of exposure/being judged \\
\hline & Do not Feel overwhelmed by additional demands \\
\hline \multirow[t]{10}{*}{ Opportunity } & Physical Opportunity A \\
\hline & Have the books and toys needed to use this new behaviour including books in home language \\
\hline & Have access to playgroups, drop-ins or other contexts to support the use of these behaviours \\
\hline & Physical Opportunity B \\
\hline & Have a family and/or social network to draw on to support them \\
\hline & Have access to/making use of childcare for siblings or child \\
\hline & Social opportunity \\
\hline & See others in their social group using the responsive communication behaviours in a range of contexts \\
\hline & Have a family and/or social network to also use the behaviours with their child \\
\hline & Have opportunities for supported 'together time' which is intrinsically rewarding for child and parents \\
\hline
\end{tabular}




\begin{tabular}{|c|c|}
\hline \multirow[t]{10}{*}{ Target behaviours for the intervention } & $\begin{array}{l}\text { Use a chosen responsive interaction behaviour for } 10 \text { - } 15 \text { minutes every day from the } \\
\text { following list: }\end{array}$ \\
\hline & - Get down to your child's level \\
\hline & - Follow your child's lead and interests \\
\hline & - Pause and wait for your child to show you what they are interested in \\
\hline & $\begin{array}{l}\text { - Listen watch and respond to their communication - this can be words, points, sounds or } \\
\text { movements }\end{array}$ \\
\hline & $\begin{array}{l}\text { - Describe what your child is doing or looking at - imagine what they are thinking and } \\
\text { feeling and say that }\end{array}$ \\
\hline & - Show them you are having fun and use an interesting voice \\
\hline & - If they do communicate, copy what they say or mean to say and add a word \\
\hline & - Try to use fewer questions and instead describe what is happening. \\
\hline & $\begin{array}{l}\text { - When you do ask questions try to keep them open - where, who when and why rather } \\
\text { than Yes No questions }\end{array}$ \\
\hline \multirow[t]{10}{*}{ Appropriate intervention contexts } & In daily routines chosen by parents/caregivers \\
\hline & - Bath time \\
\hline & - Getting out and about in the pram to the shops or park \\
\hline & - Breakfast, lunch or tea-time \\
\hline & - Nappy change time \\
\hline & - Playing with toys \\
\hline & - Sharing books \\
\hline & - At the library or toddler group \\
\hline & - Bedtimes \\
\hline & - Any other 'together time' \\
\hline $\begin{array}{l}\text { Barriers and enablers to the targeted behaviour } \\
\text { change }\end{array}$ & Listed in Table 6 \\
\hline \multirow[t]{2}{*}{ Intervention functions } & Primary functions - Training, Enablement, Modelling, Persuasion \\
\hline & Additional function - Environmental Restructuring* \\
\hline \multirow[t]{3}{*}{ Intervention delivery level/ policy categories } & Primary category - Service delivery \\
\hline & Secondary category - Communications/Marketing \\
\hline & Additional category - Fiscal and Environmental/social planning* \\
\hline \multirow{7}{*}{$\begin{array}{l}\text { Factors for equitable, acceptable, practicable } \\
\text { intervention delivery }\end{array}$} & Tailoring \\
\hline & Language and principles of shared decision-making \\
\hline & Modelling \\
\hline & Alliance and trust between practitioners and parent/caregivers \\
\hline & Inclusive \\
\hline & Motivating resources and approach \\
\hline & Aligned to current services \\
\hline
\end{tabular}

Note: * of specific relevance to families where there is a need to tackle barriers with respect to physical and social opportunities.

\section{Figures}




\section{Systematic Reviews}

Identifying effectiveness of interventions to improve language outcomes in 2-year-old children and their features.

\section{Other evidence}

Consult experts regarding wider evidence base and intervention context

Outputs: identification of relevant studies \& definition of scope and logic model of intervention

\section{Stage 2}

Qualitative review of intervention papers

Identify behaviours targeted in effective

interventions and intervention techniques.

\section{Other evidence}

Identify evidence regarding family characteristics relevant to equity of access to intervention and tailoring

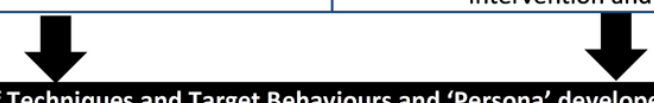

Outputs: List of Techniques and Target Behaviours and 'Persona' developed for workshops Stage 3

Co-design workshops

Explore acceptability of target behaviours and intervention approaches and issues of equity in service delivery

Outputs: List of Barriers, Enablers across families; Appraisal of acceptability of techniques and target behaviours; Identified Essential and desirable characteristics of intervention delivery Stage 4

\begin{tabular}{|c|c|}
\hline Consult Behaviour Change Theory & Consult wider theory \\
Barriers, enablers and techniques mapped to & Theory relevant to identified intervention \\
Theoretical Domains Framework; identified & delivery issues consulted (shared decision- \\
domains mapped to intervention functions and & making; therapeutic alliance; engagement; \\
policy categories & strengths-based approaches) \\
\hline
\end{tabular}

\begin{tabular}{|c|} 
policy categories \\
Output: paper 'prototype' of intervention pathway and descriptors of materials
\end{tabular}

Stage 5
Co-design workshops
'Walk through' proposed intervention with iterative development of paper prototype between
workshops and issues examined informed by previous workshop findings
Outputs: final recommendations for Intervention model and materials for development and
piloting

Figure 1

Overview of the intervention stages, outputs, and their linkage

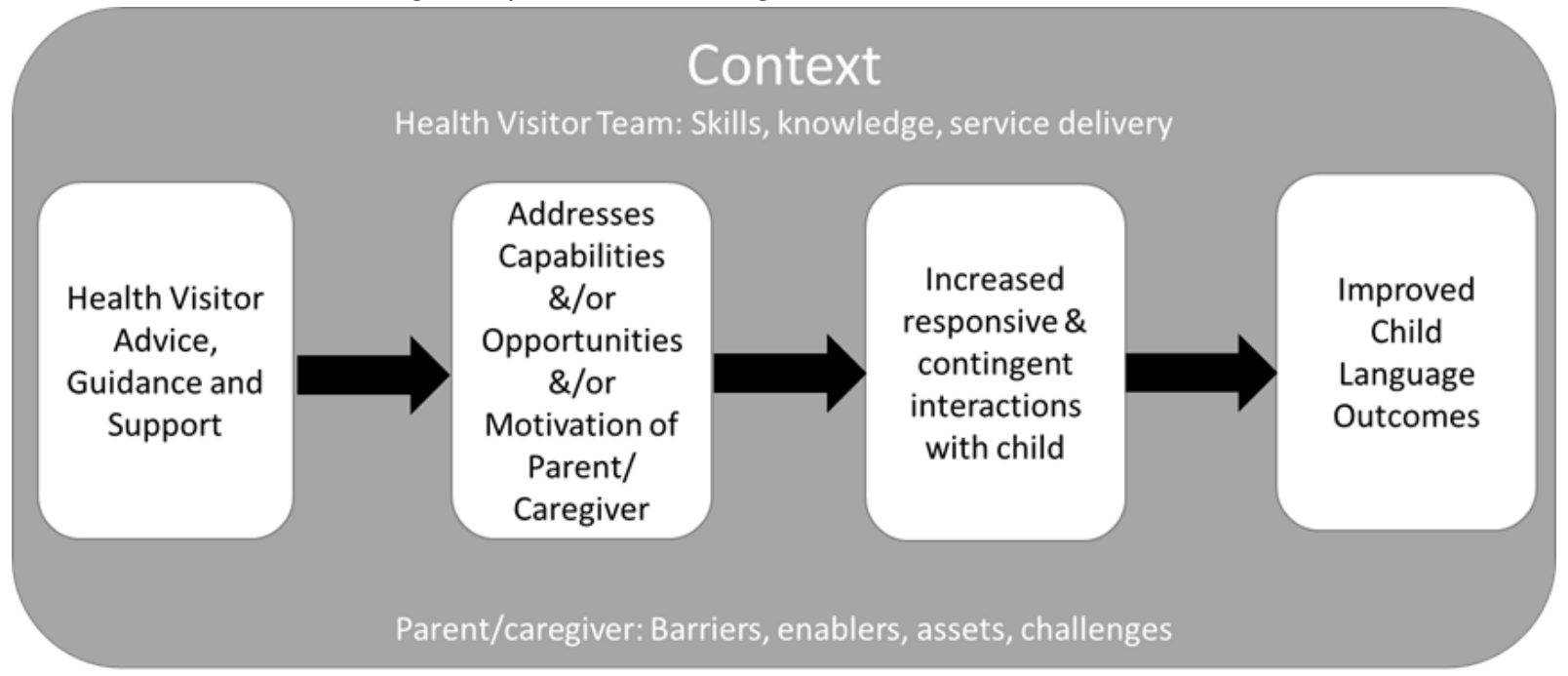

Figure 2

Simple Logic Model and to guide intervention development 


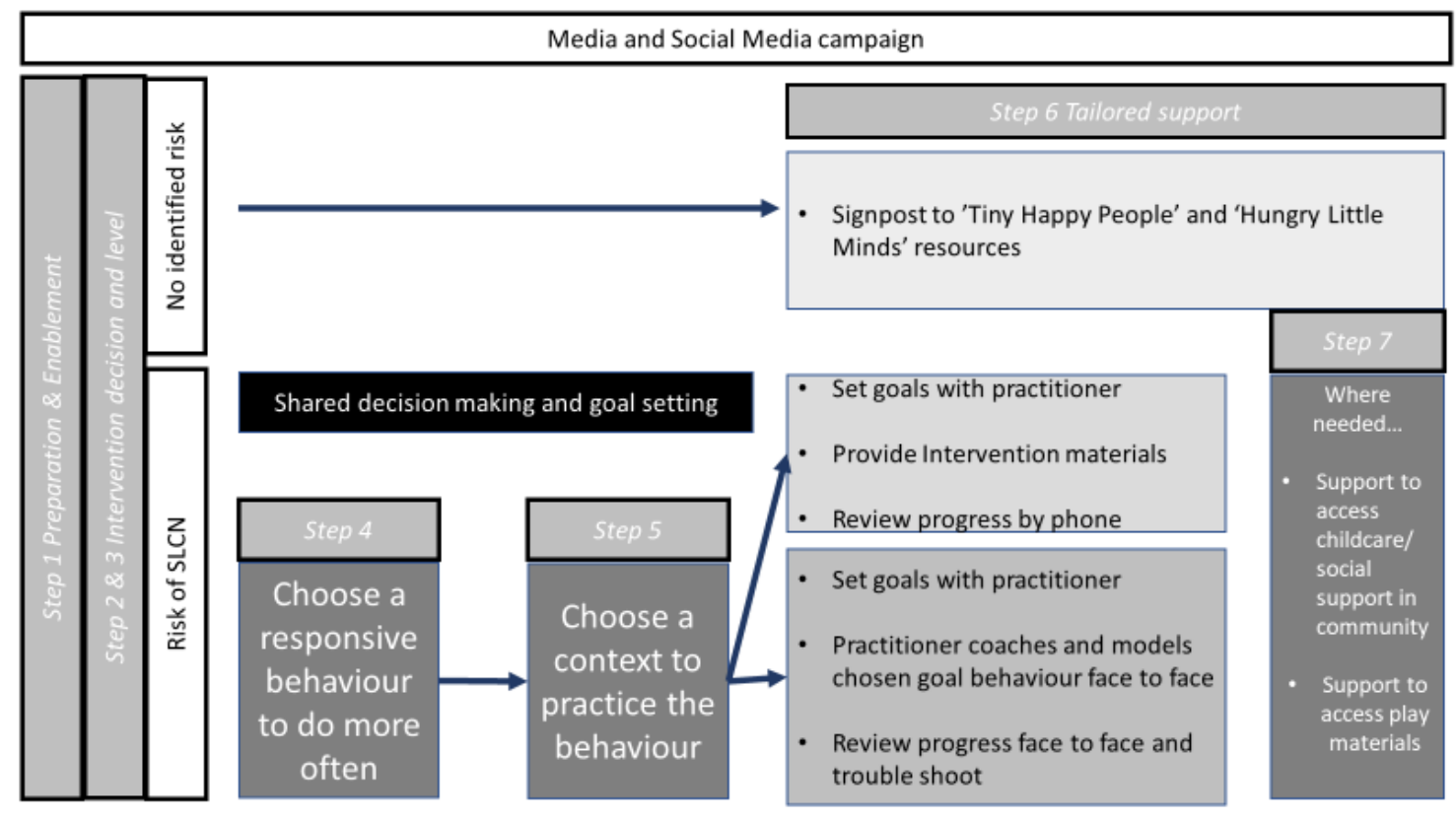

Figure 3

The proposed intervention model

\section{Supplementary Files}

This is a list of supplementary files associated with this preprint. Click to download.

- GUIDEDchecklist.pdf

- SupplementaryMaterial1.docx

- SupplementaryMaterials2.docx 